This manuscript is a preprint and has been submitted for publication in Geophysical Research Letters. If accepted, the final version of this manuscript will be available via the Peer-reviewed Publication DOI link on the righthand side of this webpage. Please feel free to contact any of the authors; we welcome feedback. 


\section{Earthquake cycle modeling of the Cascadia subduction zone}

- Ten thousand years of geometrically accurate Cascadia earthquake cycle simulations.

- Ephemeral rupture barriers due to the stress history from prior earthquakes.

- Novel model observations of "fast" slow slip events with slip rates over $1 \mu \mathrm{m} / \mathrm{s}$. 
Abstract

The Cascadia subduction zone hosts great $\mathrm{M}_{\mathrm{W}}>8.5$ earthquakes, but studying these events is hindered by our short observational record. Earthquake cycle simulation provides an alternative window into the behavior of the subduction zone. Here, we present simulations over 3,800 years, 14 ruptures and hundreds of slow slip events on a high-fidelity geometric representation of the Cascadia subduction zone beneath surface topography. The boundaries of these ruptures are defined by ephemeral stress barriers that last for several cycles but are eliminated by a barrier-crossing rupture. Thus, it is possible that many real world rupture barriers are due to remnant stress shadows from previous slip events and may not persist over several earthquake cycles. In addition, we see "fast" slow slip events with $\mathrm{M}_{\mathrm{W}} \approx 8$. These events may occur in nature and reduce the seismically available moment or they may be a spurious feature of an unrealistic friction law.

\section{Plain Language Summary}

The Cascadia subduction zone underneath Washington and Oregon has magnitude 8.5 - 9 earthquakes every 250 to 500 years. Because we only have 100 years of data, it's difficult to study the physics and statistics of this fault system. Computational earthquake cycle simulation offers a potential alternative window into the behavior of the Cascadia subduction zone. However, previous simulations have neglected the complex geometry of the fault. Here, we present ten thousand years of simulated fault behavior in the first geometrically accurate simulations of the Cascadia subduction zone. We see a wide range of fault slip behaviors, including full fault ruptures, smaller earthquake ruptures, and slow slip events. In particular, we explore the ephemeral barriers that stop earthquakes and previously undiscussed "fast" slow slip events that might reduce the earthquake potential of the fault. These Cascadia earthquake cycle simulations show the promise of a new generation of geometrically and physically realistic fault modeling in understanding and quantifying fault and earthquake behavior.

\section{Introduction}

Subduction plate boundaries host great $\mathrm{M}_{\mathrm{W}}>8.5$ earthquakes (Lay et al., 2005; Vigny et al., 2011; Simons et al., 2011). But, they also exhibit a wide range of other earthquake cycle behaviors, including smaller partial ruptures (Anderson et al., 1986; Giovanni 
et al., 2002; Yamanaka \& Kikuchi, 2003), creep (Wang et al., 2003; Schmalzle et al., 2014; Loveless \& Meade, 2016), and slow slip events (Dragert et al., 2001; Schwartz \& Rokosky, 2007). Studying the physics and statistics of these faults is very difficult because only 100 years of the earthquake cycle is captured in the modern observational record. Numerical modeling offers a potential alternative window into the earthquake cycle.

Elastic rate-and-state friction models of the earthquake cycle exhibit many of the space-time behaviors observed in subduction zones around the world. However, studies of these systems commonly assume planar geometries for the fault and Earth's surface (Liu \& Rice, 2005; Lapusta \& Liu, 2009; Segall \& Bradley, 2012; Noda \& Lapusta, 2013; Erickson \& Dunham, 2014). Fault geometry has been explored in some studies of dynamic earthquake rupture (Dunham et al., 2011; Shi \& Day, 2013), but that work has not yet been extended to models that study multiple earthquake cycles. Here, we incorporate this fundamental geometric nonlinearity into quasi-dynamic earthquake cycle models of the Cascadia subduction zone.

Seismic, geodetic and paleoseismic observations have revealed a wide range of slip behaviors on the Cascadia subduction zone. Despite the lack of major earthquakes on the plate boundary since 1700, there is significant geological (coastal subsidence, sedimentary deposits) and historical (orphan tsunami records in Japan) evidence for great earthquakes and tsunamis every 250-500 years (Satake et al., 1996; Clague, 1997; Goldfinger et al., 2012). At shorter time intervals the subduction zone exhibits intermittent localized slow slip events (Dragert et al., 2001; Miller et al., 2002) while other sections of the fault release strain continuously through creep (Wang et al., 2003; Schmalzle et al., 2014). Previous Cascadia focused quasi-dynamic earthquake cycle modeling work has demonstrated that slow slip events (SSEs) may occur spontaneously in rate and state earthquake cycle simulations on three-dimensional planar faults (Liu \& Rice, 2005). Similarly, recent short-duration $(<100$ year) simulations have demonstrated that geodetically observed slow slip events can evolve on non-planar models of the Cascadia subduction zone (Li \& Liu, 2016).

Here, we present 10,000 years of earthquake cycle simulations of the Cascadia subduction zone with geophysically constrained fault geometry and a traction-free surface representing observed topography. We use a new continuous-slip GPU-accelerated boundary element method. Because the method has no stress singularities, we can accurately 
models slip and traction on non-planar faults (Thompson \& Meade, 2019a). We adopt realistic vertical profiles of both rate-and-state frictional behavior and the pore pressure driven variations of effective normal stress (Saffer \& Tobin, 2011). These simulations exhibit a diverse range of earthquake cycle behaviors, with periods of coupling, interseismic creep, cyclic SSE behavior, $\mathrm{M}_{\mathrm{W}}=8$ partial plate boundary ruptures, and $\mathrm{M}_{\mathrm{W}}=$ 9 full plate boundary ruptures. In addition, we explore the occasional "fast" SSEs that appear in the model.

\section{Cascadia subduction zone model}

We model slip evolution on a triangulated mesh of the Cascadia subduction zone derived from Slab 1.0 (Hayes et al., 2012) consisting of 29,860 triangles (Figure 1a). The fault surface extends from approximately $1200 \mathrm{~km}$ from $40^{\circ} \mathrm{N}$ to $50^{\circ} \mathrm{N}$. The topographic free surface extends $1000 \mathrm{~km}$ away from the fault surface. The elevation data is derived from the Shuttle Radar Topography Mission provided through Tilezen and Amazon Web Services (Tilezen, 2019) and the surface is triangulated into 14,842 triangles.

We adopt the quasidynamic earthquake cycle simulation methodology (Rice, 1993) combined with rate-state friction and the aging law for state evolution (Dieterich, 1979; Ruina, 1983). The quasidynamic approximation neglects the full wave-mediated stress transfer during rupture and instead approximates it with a radiation damping term that represents the local drop in stress due to slip. The quasidynamic approximation allows modeling thousands of years of fault evolution efficiently. On the other hand, it produces some qualitative differences in the shape and slip speed of ruptures (Thomas et al., 2014). Similar to the model of (Liu \& Rice, 2005), the critical $a$ and $b$ parameters vary with depth. This includes velocity strengthening effects above and below $5 \mathrm{~km}$ depth to $35 \mathrm{~km}$ depth while the intermediate depth region is velocity weakening and capable of nucleating ruptures (Figure 1b). We use typical values for other material and frictional parameters: $\mu=$ $20 \mathrm{GPa}, \nu=0.25, \rho=2670 \mathrm{~kg} / \mathrm{m}^{3}, V_{0}=10^{-6} \mathrm{~m} / \mathrm{s}, f_{0}=0.6$ and $D_{c}=0.075$.

The magnitude of relative motion between the Juan de Fuca and North American plates varies from $29.8 \mathrm{~mm} / \mathrm{yr}$ at the southern end to $39.7 \mathrm{~mm} / \mathrm{yr}$ at the northern end of the fault with a direction $\sim 60^{\circ}$ east of north (DeMets \& Dixon, 1999; Miller et al., 2001). This plate convergence rate varies in relation to the dip vector on the fault sur- 

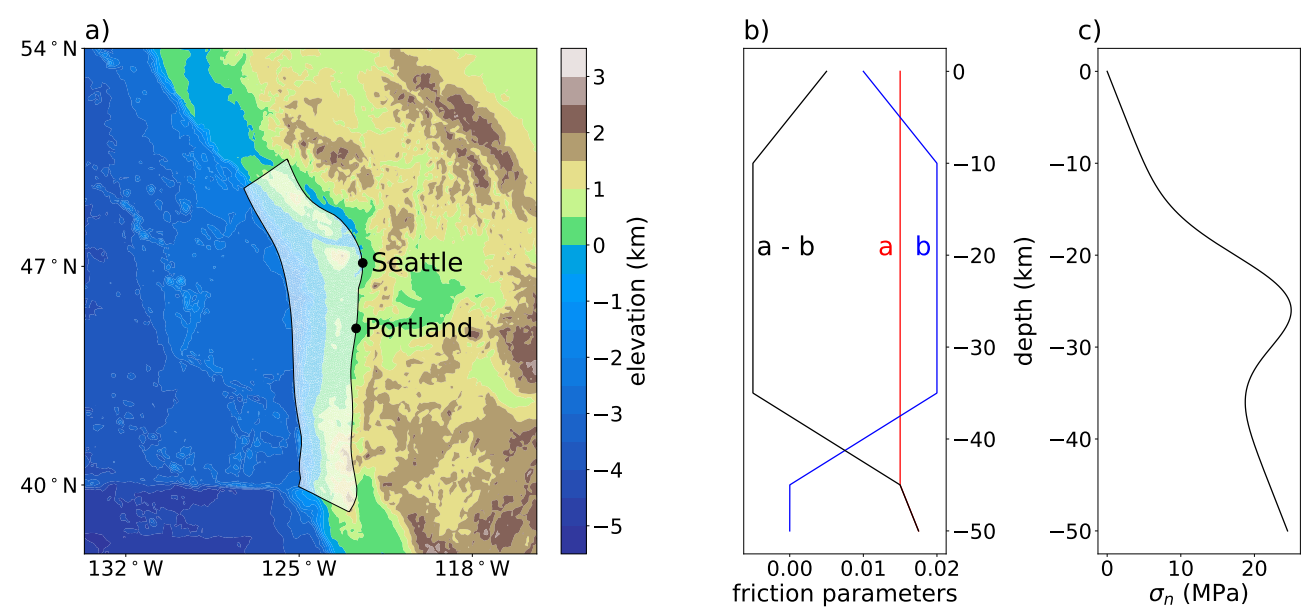

Figure 1. Left: A map showing the location of the Cascadia fault mesh, the topography in the general vicinity and the locations of Seattle and Portland. Middle: The friction parameters, $a$ and $b$ and the difference, $a-b$ as a function of depth. $a-b$ is negative and thus the fault is velocity weakening between $5 \mathrm{~km}$ depth and $40 \mathrm{~km}$ depth. In the shallower and deeper portions of the fault, $a-b$ is positive and the fault is velocity strengthening. Right: a profile of the baseline effective normal stress as a function of depth.

face. We allow the slip rake to vary freely in accordance with the direction of highest shear stress at each point on the fault surface.

We impose an effective normal stress profile following Saffer and Tobin (2011) in assuming very high fluid overpressure at shallow and deep depths with somewhat less overpressure in the middle depths (Figure 1c). Unlike many previous earthquake cycle simulations, we allow the normal stress on the fault to vary as a result of nearby slip. With purely shear slip on a planar fault, there is no normal stress perturbation on the fault surface. However, due to the continuity of slip, the slip at a bend in the fault surface cannot be purely tangential to two different planes. As a result, there is a small component of tensile motion that perturbs the normal stress on the fault.

We run the primary model for 100,000 time steps or 10,864 years. To solve for the stress at each time step, we use a new continuous-slip boundary element method that accurately represents both stress and slip on the fault surface without any stress singularities (Thompson \& Meade, 2019a). To update the fault slip and state variables in time, we use an adaptive Runge-Kutta 2(3) algorithm (Bogacki \& Shampine, 1989) with a time 
step tolerance of $10^{-4}$. Because we initiate the model with no slip deficit and thus no stress, the fault is slowly evolving towards a steady state zone of behavior for the first 6,500 years. To be conservative and avoid the influence of the initial conditions, we focus our discussion on the evolution of slip after model year 7,000. There are 14 major ruptures during this period along with frequent SSEs including three "fast" SSEs.

\section{Discussion}

The results of our simulations are most easily visualized as animations available on YouTube (Thompson \& Meade, 2019b). However, we present summary figures of a representative earthquake cycle beginning with a rupture at year 7,713 (Figure 2a). This rupture initiates in the southern half of the subduction zone and is propagating northwards. The rupture spans all the way to the trench and $6 \mathrm{~km}$ down dip into the deep velocity strengthening zone. The rupture is slipping fastest $(>0.1 \mathrm{~m} / \mathrm{s})$ near its propagation front, while earlier portions of the rupture slow to $1 \mathrm{~mm} / \mathrm{s}$. The state variable drops to 0.4 in the fastest moving portions of the rupture representing a decrease in the frictional resistance to slip. The rupture eventually arrests at approximately the latitude of Portland.

Immediately after the rupture, afterslip continues around the edges of the ruptured area (Figure $2 \mathrm{~b}$ ). The afterslip asymptotically decreases in velocity over the next 10 years. While the afterslip slows it also spreads outward spatially, eventually extending more than $100 \mathrm{~km}$ along strike from the area that ruptured. The afterslip eventually extends all the way to the deepest portions of the fault, accelerating those strongly velocity strengthening regions to almost 20 times the plate motion rate. In a different earthquake cycle beginning with a rupture at model year 8,180, the last remnants of the afterslip zone spreads over $200 \mathrm{~km}$ south of the main rupture and triggers a second rupture 61 years later. 

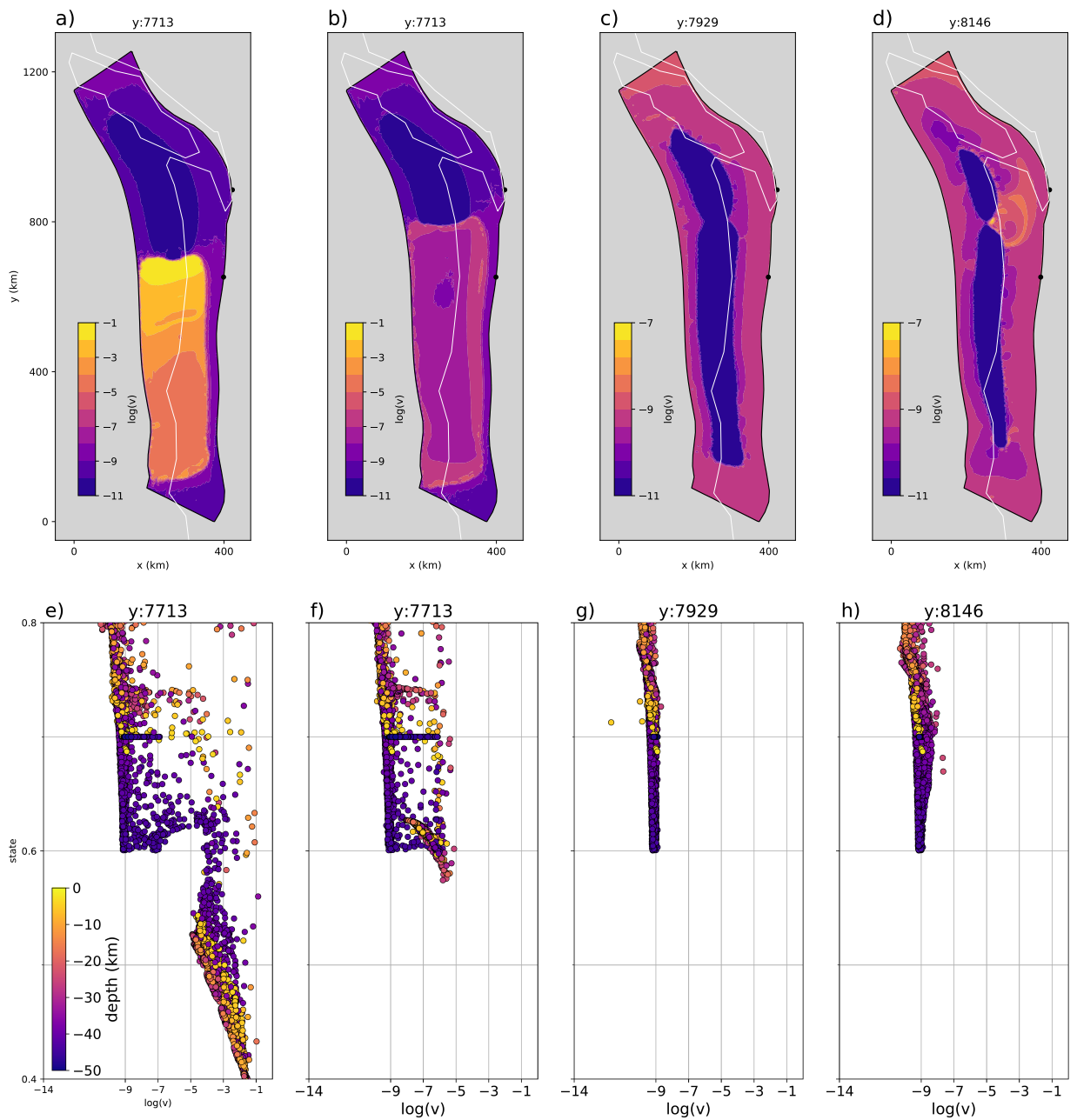

Figure 2. In the first row (a-d) the base $10 \log$ slip velocity on the fault is shown at four different snapshots in time during a single representative earthquake cycle. For reference, a slip velocity of $10^{-9} \mathrm{~m} / \mathrm{s}$ is approximately equal to $32 \mathrm{~mm} / \mathrm{yr}$ and thus is similar to the rate of plate motion. The two black dots show the locations of Seattle and Portland and the white line indicates the coastline. In the second row (e-h), the distribution of slip velocity against state is shown for the same points in time. a,e) a rupture propagating from south to north. b,f) postseismic afterslip. c,g) a period of interseismic locking. d,h) a slow slip event propagating bilaterally. Note that the color scale bar is different between panels a), b) and panels c), d).

At 216 years after the rupture, most of the middle depths of the fault are locked, while the deeper and some portions of the shallow fault are creeping at approximately the plate rate (Figure 2c). The outlines of the previous rupture define the most locked portion of the subduction zone. Another locked zone further north outlines the extent 
of the penultimate ruptures. This spatial mosaicing is indicative of the historical control on the extent of future ruptures.

At 433 years after the rupture, there is slow slip event propagating bilaterally underneath the Olympic Peninsula (Figure 2d). Simultaneously, the most strongly coupled region decreased in down-dip width by nine $\mathrm{km}$. Seven more slow slip events will occur before the fault eventually ruptures again at year 8,180 .

The coupling erosion of the locked zone (Figure 2c and Figure 2d) is a general feature of these earthquake cycle models (Segall \& Bradley, 2012; Mavrommatis et al., 2015). Immediately after a rupture, the entire ruptured area will become locked. During the interseismic phase, the locked zone will shrink in size. Once the locked zone is small enough, slow slip events will begin nucleating along the edges until eventually enough stress has accumulated to trigger the initiation of another rupture.

Importantly, with are 14 ruptures in our model over 3,800 years (Figure 3), the recurrence interval of 271 years in this model is similar to paleoseismic estimates of recurrence (Clague, 1997). The ruptures range from unlocking $20 \%$ to $80 \%$ of the fault surface with most only rupturing either the northern or southern half of the fault. The magnitudes range from $\mathrm{M}_{\mathrm{W}}=8.7$ to 9.1 with maximum slip of almost 20 meters and along strike lengths up to $900 \mathrm{~km}$.

Much work has been dedicated to the causes of real world rupture barriers (Noda \& Lapusta, 2013; Protti et al., 2014; Loveless \& Meade, 2015). In the model we present here, there are clear boundaries at which the ruptures arrest (Figure 3). These boundaries persist over several earthquake cycles, but are not permanent. These ephemeral boundaries are controlled by the stress field with a recently ruptured patch not rupturing in the next event because the stress level has not yet risen sufficiently to continue propagation. The barriers are eventually eliminated by a rupture crossing the barrier. Over the next one or two earthquake cycles, a new barrier evolves. Thus, it is possible that many real world rupture barriers are due to the remnant stress shadow from previous slip events and may not persist over several earthquake cycles.

In addition to this primary model, we have run several other models with slightly different parameter sets. In particular, we have a model with a planar free surface and planar megathrust. While most of the same slip behaviors are present in that model, the 

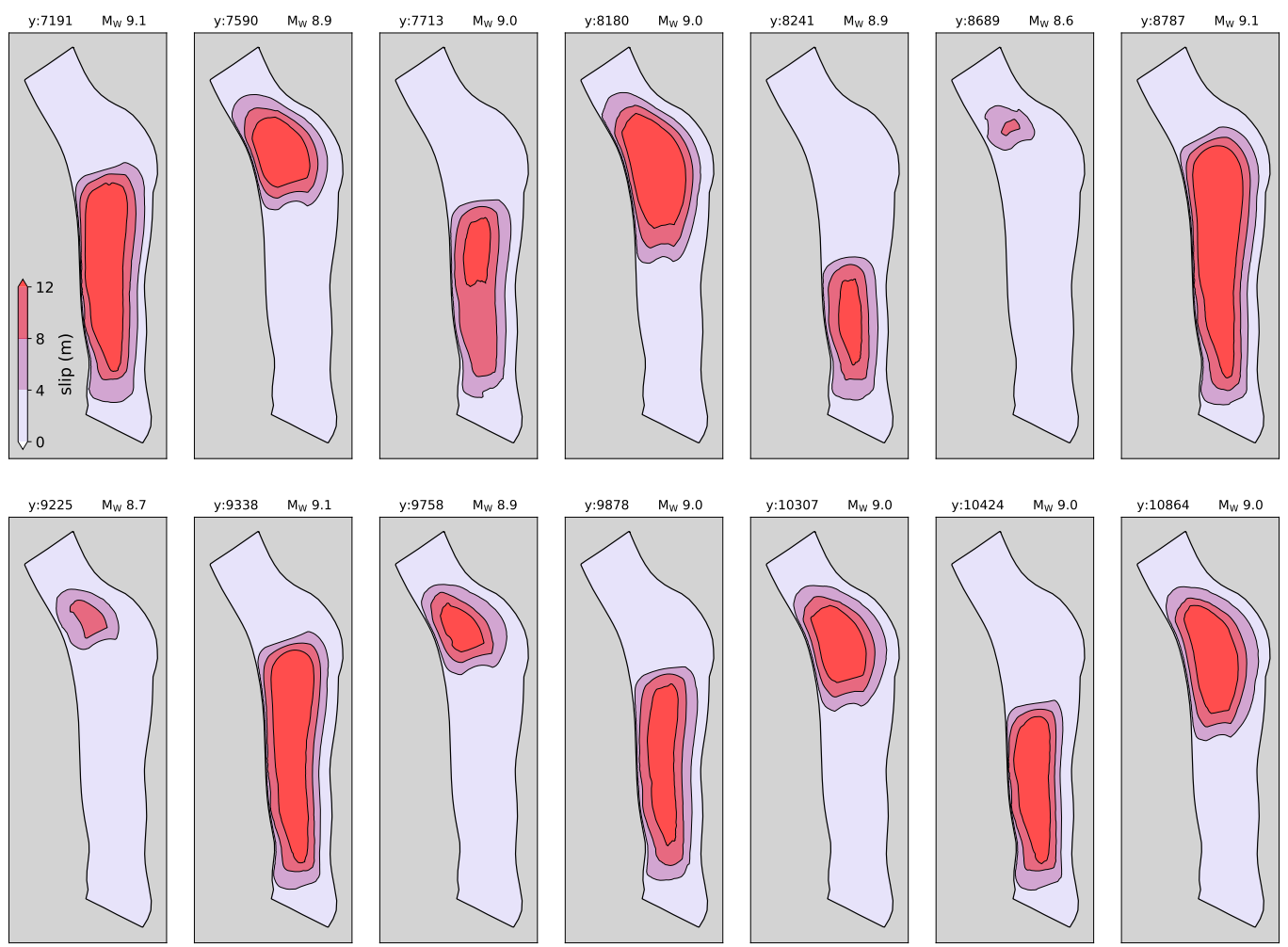

Figure 3. The extent and slip magnitude during each rupture. The year and model magnitude for each rupture are displayed above the diagrams.

ruptures have simpler patterns and behave in a more consistently cyclic pattern. The nonplanar geometry is introducing some acyclic behavior into the model that is not present in the planar equivalent.

We have also run models with a reduction in the degree of velocity weakening behavior. These models behave as expected, with a lower propensity to rupture and larger regions of decoupled creep. We have run models with a normal stress profile that is perfectly linear with depth rather than having higher effective normal stress at middle depths. Those models behave almost identically except the nucleation point of ruptures is $2-6$ $\mathrm{km}$ shallower.

Finally, we have run a model with four times higher effective normal stress. This model demonstrates that the rupture and slip magnitudes depend linearly on the assumed effective normal stress on the fault surface. In this higher stress model, the recurrence interval is 1,100 years and the slip per event is four times larger with peak slip magnitudes over 100 meters. These unrealistic results from a high stress model suggest that 
the Cascadia subduction zone may have very low effective normal stress and is in agreement with observational evidence (Hardebeck, 2015; Audet et al., 2009).

On the other hand, the main control on the recurrence interval in our models is the fault strength. Decreasing effective normal stress decreases the fault strength, but decreasing the baseline friction coefficient ( $f_{0}$ in the rate and state equations) would also decrease the fault strength. Another way to reduce coseismic slip magnitudes is to have a mix of velocity weakening and velocity strengthening zones or simply have a slightly less velocity weakening friction parameters. It is also worth wondering whether these large slip magnitudes are an artifact of the quasidynamic approximation. However, in a fully dynamic model, total slip would likely be even higher than in these quasidynamic models due to higher dynamically supported slip velocities during rupture (Thomas et al., 2014).

\section{Fast slow slip events}

A striking feature of the model is the occasional "fast" SSE occuring on the northern most portion of the subduction zone. These events have slip rates over $1 \mu \mathrm{m} / \mathrm{s}$ but below the $1 \mathrm{~mm} / \mathrm{s}$ characteristic of a seismic rupture. We see these events at year 9,059, 9,618 and 10,731 . These events have the moment release equivalent to $\mathrm{M}_{\mathrm{W}} \approx 8$ ruptures. We believe it is unlikely that the quasidynamic approximation is affecting the presence of these events because the slip rates are several orders of magnitude below normal seismic rupture velocities. Despite this, it should be confirmed that these fast SSEs also occur in fully dynamic earthquake cycle models.

No such fast SSEs have been yet been observed during the geodetic era ( $~ 30$ years). However, these events are predicted to occur only every thousand years in our model and would not produce significant ground shaking. So, it's possible that no such fast SSEs have occured during our short window of modern geodetic observation. In the paleoseismic record, uplift would occur in a short enough period of time that it might be confused for a rupture, but there would be no evidence of a tsunami (Nelson et al., 2006). Subduction zones that host fast SSEs may have less seismic hazard than otherwise predicted.

On the other hand, if these fast SSEs never occur in nature, that provides useful constraints on frictional behavior. With improved regional modeling capabilities, we may be able to rule out certain sets of rate and state frictional parameters because those pa- 
rameters predict unrealistic events. More generally, with improved realism, we can use earthquake cycle modeling techniques to identify likely models of frictional behavior and stress states on faults. While there may be a large null space, many frictional behaviors and parameter sets can be ruled out because they do not explain the shapes, sizes, range or frequency of slip events that we observe.

\section{Conclusions}

Realistic earthquake cycle models including accurate fault geometry and surface topography will lead to a better understanding of the crucial role played by these first order nonlinearities in the evolution of earthquake cycles. Here, we discuss earthquake cycle simulations on an high-fidelity geometric representation of the Cascadia subduction zone beneath true surface topography. Over the 3,800 years of spun-up model time, we observe great 14 earthquakes. The boundaries of these ruptures are defined by ephemeral rupture barriers. These barriers are defined by the stress field produced by previous ruptures and eventually are eliminated by a barrier crossing rupture. In addition to many $\mathrm{M}_{\mathrm{W}}=6-7$ slow slip events, we see occasional "fast" slow slip events with $\mathrm{M}_{\mathrm{W}} \approx 8$. These are a new type of slip behavior, previously undiscussed. These "fast" slow slip events may occur in nature and reduce the seismically available moment or they may be a spurious feature of an unrealistic friction law. Regardless, these Cascadia earthquake cycle models show the promise of a new generation of geometrically and physically realistic fault modeling in understanding and quantifying fault slip behavior of all types in a unified setting.

\section{Acknowledgments}

The data and source code for this work is available at https://github.com/tbenthompson/qd.

T. Ben Thompson appreciates the support of the Department of Energy Computational Science Graduate Fellowship.

\section{References}

Anderson, J., Bodin, P., Brune, J., Prince, J., Singh, S., Quaas, R., \& Onate, M. (1986). Strong ground motion from the michoacan, mexico, earthquake. Science, 233(4768), 1043-1049.

Audet, P., Bostock, M. G., Christensen, N. I., \& Peacock, S. M. (2009). Seismic ev- 
idence for overpressured subducted oceanic crust and megathrust fault sealing. Nature, 457(7225), 76.

Bogacki, P., \& Shampine, L. F. (1989). A 3 (2) pair of runge-kutta formulas. Applied Mathematics Letters, 2(4), 321-325.

Clague, J. J. (1997). Evidence for large earthquakes at the cascadia subduction zone. Reviews of Geophysics, 35(4), 439-460.

DeMets, C., \& Dixon, T. H. (1999). New kinematic models for pacific-north america motion from 3 ma to present, i: Evidence for steady motion and biases in the nuvel-1a model. Geophysical Research Letters, 26(13), 1921-1924.

Dieterich, J. H. (1979). Modeling of rock friction: 1. experimental results and constitutive equations. Journal of Geophysical Research: Solid Earth, 84(B5), 21612168.

Dragert, H., Wang, K., \& James, T. S. (2001). A silent slip event on the deeper cascadia subduction interface. Science, 292(5521), 1525-1528.

Dunham, E. M., Belanger, D., Cong, L., \& Kozdon, J. E. $\quad$ (2011). ～Earthquake ruptures with strongly rate-weakening friction and off-fault plasticity, part 2: Nonplanar faults. Bulletin of the Seismological Society of America, 101 (5), $2308-2322$.

Erickson, B. A., \& Dunham, E. M. (2014). An efficient numerical method for earthquake cycles in heterogeneous media: Alternating subbasin and surfacerupturing events on faults crossing a sedimentary basin. Journal of Geophysical Research: Solid Earth, 119(4), 3290-3316.

Giovanni, M. K., Beck, S. L., \& Wagner, L. (2002). The june 23, 2001 peru earthquake and the southern peru subduction zone. Geophysical Research Letters, $29(21), 14-1$.

Goldfinger, C., Nelson, C. H., Morey, A. E., Johnson, J. E., Patton, J., Karabanov, E., ... others (2012). Turbidite event historymethods and implications for holocene paleoseismicity of the cascadia subduction zone.

Hardebeck, J. L. (2015). Stress orientations in subduction zones and the strength of subduction megathrust faults. Science, 349 (6253), 1213-1216.

Hayes, G. P., Wald, D. J., \& Johnson, R. L. (2012). Slab1. 0: A three-dimensional model of global subduction zone geometries. Journal of Geophysical Research: Solid Earth, 117(B1). 
Lapusta, N., \& Liu, Y. (2009). Three-dimensional boundary integral modeling of spontaneous earthquake sequences and aseismic slip. Journal of Geophysical Research: Solid Earth, 114(B9).

Lay, T., Kanamori, H., Ammon, C. J., Nettles, M., Ward, S. N., Aster, R. C., ... others (2005). The great sumatra-andaman earthquake of 26 december 2004. Science, 308(5725), 1127-1133.

Li, D., \& Liu, Y. (2016). Spatiotemporal evolution of slow slip events in a nonplanar fault model for northern cascadia subduction zone. Journal of Geophysical Research: Solid Earth, 121(9), 6828-6845.

Liu, Y., \& Rice, J. R. (2005). Aseismic slip transients emerge spontaneously in three-dimensional rate and state modeling of subduction earthquake sequences. Journal of Geophysical Research: Solid Earth, 110(B8).

Loveless, J. P., \& Meade, B. J. (2015). Kinematic barrier constraints on the magnitudes of additional great earthquakes off the east coast of japan. Seismological Research Letters, 86 (1), 202-209.

Loveless, J. P., \& Meade, B. J. (2016). Two decades of spatiotemporal variations in subduction zone coupling offshore japan. Earth and Planetary Science Letters, $436,19-30$.

Mavrommatis, A. P., Segall, P., Uchida, N., \& Johnson, K. M. (2015). Long-term acceleration of aseismic slip preceding the mw 9 tohoku-oki earthquake: Constraints from repeating earthquakes. Geophysical Research Letters, 42(22), 9717-9725.

Miller, M. M., Johnson, D. J., Rubin, C. M., Dragert, H., Wang, K., Qamar, A., \& Goldfinger, C. (2001). Gps-determination of along-strike variation in cascadia margin kinematics: Implications for relative plate motion, subduction zone coupling, and permanent deformation. Tectonics, 20(2), 161-176.

Miller, M. M., Melbourne, T., Johnson, D. J., \& Sumner, W. Q. (2002). Periodic slow earthquakes from the cascadia subduction zone. Science, 295(5564), $2423-2423$.

Nelson, A. R., Kelsey, H. M., \& Witter, R. C. (2006). Great earthquakes of variable magnitude at the cascadia subduction zone. Quaternary Research, 65(3), 354365.

Noda, H., \& Lapusta, N. (2013). Stable creeping fault segments can become destruc- 
tive as a result of dynamic weakening. Nature, $493(7433), 518$

Protti, M., González, V., Newman, A. V., Dixon, T. H., Schwartz, S. Y., Marshall, J. S., ... Owen, S. E. (2014). Nicoya earthquake rupture anticipated by geodetic measurement of the locked plate interface. Nature Geoscience, $7(2)$, 117.

Rice, J. R. (1993). Spatio-temporal complexity of slip on a fault. Journal of Geophysical Research: Solid Earth, 98(B6), 9885-9907.

Ruina, A. (1983). Slip instability and state variable friction laws. Journal of Geophysical Research: Solid Earth, 88(B12), 10359-10370.

Saffer, D. M., \& Tobin, H. J. (2011). Hydrogeology and mechanics of subduction zone forearcs: Fluid flow and pore pressure. Annual Review of Earth and Planetary Sciences, 39, 157-186.

Satake, K., Shimazaki, K., Tsuji, Y., \& Ueda, K. (1996). Time and size of a giant earthquake in cascadia inferred from japanese tsunami records of january 1700 . Nature, $379(6562), 246$.

Schmalzle, G. M., McCaffrey, R., \& Creager, K. C. (2014). Central cascadia subduction zone creep. Geochemistry, Geophysics, Geosystems, 15(4), 1515-1532.

Schwartz, S. Y., \& Rokosky, J. M. (2007). Slow slip events and seismic tremor at circum-pacific subduction zones. Reviews of Geophysics, 45(3).

Segall, P., \& Bradley, A. M. (2012). Slow-slip evolves into megathrust earthquakes in 2d numerical simulations. Geophysical Research Letters, $39(18)$.

Shi, Z., \& Day, S. M. (2013). Rupture dynamics and ground motion from 3-d roughfault simulations. Journal of Geophysical Research: Solid Earth, 118(3), 11221141.

Simons, M., Minson, S. E., Sladen, A., Ortega, F., Jiang, J., Owen, S. E., ... others (2011). The 2011 magnitude 9.0 tohoku-oki earthquake: Mosaicking the megathrust from seconds to centuries. science, 332(6036), 1421-1425.

Thomas, M. Y., Lapusta, N., Noda, H., \& Avouac, J.-P. (2014). Quasi-dynamic versus fully dynamic simulations of earthquakes and aseismic slip with and without enhanced coseismic weakening. Journal of Geophysical Research: Solid Earth, $119(3)$, 1986-2004.

Thompson, T. B., \& Meade, B. J. $\quad$ (2019a, Apr). Boundary element methods for earthquake modeling with realistic $3 d$ geometries. EarthArXiv. Retrieved from 
eartharxiv.org/xzhuk doi: 10.31223/osf.io/xzhuk

Thompson, T. B., \& Meade, B. J. (2019b, Apr 2). Cascadia earthquake cycle simulation. https://www. youtube. com/watch?v=ieN-9MUhND8.

Tilezen. (2019). Tilezen: Open source tiles and libraries, sponsored by mapzen and now a linux foundation project. https://github.com/tilezen. (Accessed: 2019-03-19)

Vigny, C., Socquet, A., Peyrat, S., Ruegg, J.-C., Métois, M., Madariaga, R., ... others (2011). The $2010 \mathrm{mw} 8.8$ maule megathrust earthquake of central chile, monitored by gps. Science, 332(6036), 1417-1421.

Wang, K., Wells, R., Mazzotti, S., Hyndman, R. D., \& Sagiya, T. (2003). A revised dislocation model of interseismic deformation of the cascadia subduction zone. Journal of Geophysical Research: Solid Earth, $108(\mathrm{~B} 1)$.

Yamanaka, Y., \& Kikuchi, M. (2003). Source process of the recurrent tokachioki earthquake on september 26, 2003, inferred from teleseismic body waves.

Earth, Planets and Space, 55(12), e21-e24. 